\title{
Prevalence and disparities in the first dental visit of preschool children aged 12-18 months in southern Brazil
}

\author{
Prevalência e disparidades na primeira visita odontológica de \\ pré-escolares de 12 a 18 meses no sul do Brasil
}

Andréia Drawanz Hartwig*
Marina Sousa Azevedo**
Ana Regina Romano
Maximiliano Sérgio Cenci

\begin{abstract}
Objective: this study aimed to assess the use of dental services in a southern Brazilian city by children aged 12-18 months and to verify the relationship between socioeconomic and demographic variables, as well as maternal use of dental services, and presence of dental caries in the children. It also aimed to describe the prevalence of use of dental services by variables of disparity. Subjects and method: this cross-sectional study was performed on the National Children's Vaccination Day in 12 public health care centers in Pelotas, RS, Brazil. The data on demographic and socioeconomic status (children's sex, number of children, family income, and maternal education), pattern of maternal use of dental services, and children's first dental visit were collected using a semi-structured interview answered by the mothers. Clinical examination was performed to assess dental caries in the children. Chi-square and Fisher's exact tests were performed to analyze the associations and an equiplot graph investigated disparities in the prevalence of the first dental visit of preschoolers. Results: most children had never been to the dentist (93.4\%). The bivariate analysis showed that children who had never been to the dentist belonged to families with lower income, and their mothers presented low level of education and did not use dental services. Conclusion: most children aged 12-18 months had never been to the dentist and there is a socioeconomic disparity in the use of dental services by preschool children.
\end{abstract}

Keywords: Child. Dental services. Preventive dentistry. Preschool.

\section{Introduction}

Early dental care may be an important strategy to reduce the incidence of several oral disorders that may occur during childhood ${ }^{1}$. The American Academy of Pediatric Dentistry has advocated that children should see a dentist at one year of age for dental screenings in order to promote the early prevention of oral diseases ${ }^{1}$. This first dental visit may be strategic to establish the primary prevention actions for caregivers and to provide parental education ${ }^{1}$.

Early prevention may translate into significant financial savings on dental care. Children who had an early preventive dental visit are more likely to use subsequent preventive services and experience less dental-related $\operatorname{costs}^{2}$. Moreover, findings from epidemiological studies that had been conducted worldwide show that a small percentage of children had been to the dentist before one year of age $\mathrm{e}^{3-7}$. The prevalence of first dental visit at 12 months varied from $1 \%$ to $4.3 \%$,

From 1987 to 2011, children's lack of access to dentists has decreased, but their first dental visit is still concerning. Studies have indicated socioeconomic disparities in the use of dental services ${ }^{8,9}$. Regarding children, few studies have addressed this issue. Some studies have associated low family income, low maternal level of education, irregular maternal use of dental services, and higher number of children in the family presenting late use of den-

\footnotetext{
PhD student, Graduate Program in Dentistry, Federal University of Pelotas, Pelotas, Rio Grande do Sul, Brazil.

Professor, Graduate Program in Dentistry, Federal University of Pelotas, Pelotas, Rio Grande do Sul, Brazil.

Professor, Graduate Program in Dentistry, Federal University of Pelotas, Pelotas, Rio Grande do Sul, Brazil.

Professor, Graduate Program in Dentistry, Federal University of Pelotas, Pelotas, Rio Grande do Sul, Brazil.
} 
tal services, but there is still no consensus in the literature ${ }^{6-8,10}$.

Since 2004, Brazil has implemented extensive changes to the oral health system. The Brazilian oral health policy ("Smiling Brazil") was launched under new principles and the reorientation of working processes, and specialized programs for children were implemented ${ }^{11}$. From a public health perspective, the use of dental services by children might serve as an important parameter to assess the impact of the oral health policies.

Thus, this study aimed to assess the use of dental services in a southern Brazilian city by children aged 12-18 months and to verify the relationship between socioeconomic and demographic variables, as well as maternal use of dental services and presence of dental caries in the children. It also aimed to describe the prevalence of use of dental services by variables of disparity.

\section{Sulbjects and method}

\section{Study design and setting}

This cross-sectional study was nested in a clinical trial in Pelotas, which is a city located in the south region of Brazil with 328,275 inhabitants and 93\% of the population living in the urban area, to assess the effectiveness of an educative intervention for preventing early childhood caries (ECC) ${ }^{12}$. The data for this study were collected before the intervention.

The study was performed on the National Children's Vaccination Day. In Brazil, child vaccination is performed extensively in public health centers (PHCs) regardless of the family's socioeconomic conditions. The vaccination program in the city of Pelotas had an uptake rate of 90 percent among children up to 59 months old. Among the 52 municipal public health centers, 35 offer dental services (11 in the rural area and 24 in the urban area). From the 35 PHCs that offer dental services, 12 were randomly selected from the urban area $(93 \%$ of children live in the urban area) using a computer-generated list of random numbers. The study focused on mothers of children aged 12-18 months. Mothers who did not live in Pelotas, children unaccompanied by mothers, and those with neurological or systemic diseases were not included.

\section{Interview}

Data were collected using a semi-structured and pretested face-to-face interview. Twenty-four dentists and dental students were trained previously in two sessions ( $4 \mathrm{~h}$ each), in which the students read the questionnaire and the instruction manual and conducted simulated interviews. The interviews were conducted in a private room after the child had been vaccinated. In addition, mothers re- ceived a brief explanation about early childhood caries (ECC) prevention and an educational pamphlet with further information.

The mothers answered their interview, which included questions on demographic and socioeconomic data (children's sex, number of children, family income, and maternal education), pattern of the use of dental services, and children's first dental visit. Information about family income was collected from each parent and transformed in terms of the Brazilian minimum wage (BMW), which corresponded to approximately 285 USA dollars a month at the time of data collection. The total income was categorized in tertiles, considering the first tertile represents the poorest portion of the sample $(0-1.3$ BMW) and the third tertile is the richest portion (2.5 - 22 BMW). Maternal level of education was categorized into years of education under or equal to 8 years, $9-11$ years, 12 years or more. Data on the number of children were also collected and categorized as one child, two children, and three children or more. Data about children's dental visit was collected through the following questions: "Has your child ever been to the dentist?", which answer choices were yes or no; and "How old was the child when he/she went to the dentist for the first time?", which was an open-ended question categorized in one year old or less or more than one year old, in order to assess children who had visited the dentist during the first year of life. Data about the maternal use of dental services were collected through the following question: "How would you define your visits to the dentist?" (1- I never go to the dentist; 2- I go to the dentist when I feel pain or when I have a problem with my teeth or gums; 3- I go to the dentist sometimes, whether I have a problem or not; 4- I go to the dentist regularly). The answers were categorized in "Never goes to the dentist" (Answer 1), "In the presence of pain or a problem" (Answers 2), and "Sometimes/Regularly" (Answers 3 and 4) (10).

\section{Clinical examination}

The examinations were performed by a team of 12 dentists and advanced dental students. All examiners were calibrated and completed a 4 -h theoretical training session. To perform the calibration, 10 children outside the main sample were examined by the staff members and by one gold-standard examiner with previous experience in epidemiological studies (ARR). The mean inter-examiner kappa was 0.83 and the mean intra-examiner kappa was 0.93 . The dental offices of the PHCs were used to perform the clinical examinations. Before the examination, the children's teeth were cleaned with gauze, dried with compressed air, and examined under artificial light. Each tooth surface in the mouth was then inspected for dental caries ${ }^{13}$. For ECC, only the maxillary anterior teeth were inspected ${ }^{14}$, because the white spot lesions usually start at the cervical 
third of upper anterior teeth and the oral moisture could be controlled the best in this region. White lesions were defined as any sign of whitish opaque coloration close to the gingival margin that showed roughness when the probe was moved gently across the surface ${ }^{15}$. All teeth visible in the mouth were recorded. Children without caries were categorized as $\mathrm{ECC}=0$. Children with one decayed (cavitated and/ or non-cavitated for the maxillary anterior surface), missing, and filled surface index were categorized as $\mathrm{ECC}=1$. Children with more than one decayed (cavitated and/or non-cavitated for the maxillary anterior surface), missing, and filled surface index were categorized as $\mathrm{ECC} \geq 2$.

\section{Statistical analysis}

Descriptive and analytical approaches were conducted using the Stata software, version 9.1 (Stata Corporation, College Station, TX, USA) for data analysis. The chi-square and Fisher's exact tests were used to assess differences in the frequencies of independent variables and the outcome (children who had never been to the dentist).

Inequalities in the prevalence of the first dental visit of preschool children were investigated in three categories of inequality (c) - $\mathrm{c} 1$ being the worst condition and $\mathrm{c} 3$ the best condition. The three dimensions are number of children ( $c 1=\geq 3$ children, $\mathrm{c} 2=2$ children, and $\mathrm{c} 3=1$ children), maternal level of education ( $\mathrm{c} 1=\leq 8$ years, $\mathrm{c} 2=9-11$ years, and $\mathrm{c} 3=\geq 12$ years), family income ( $\mathrm{c} 1=1^{\circ}$ Tertile (poorest), $\mathrm{c} 2=2^{\circ}$ Tertile, and $\mathrm{c} 3=3^{\mathrm{o}}$ Tertile (richest)), maternal use of dental services $(c 1=$ Never goes to the dentist, $c 2=$ In the presence of pain or a problem, and $\mathrm{c} 3=$ Sometimes/Regularly), and early childhood caries (c1= $\mathrm{ECC} \geq 2, \mathrm{c} 2=\mathrm{ECC}=1$, and $\mathrm{c} 3=\mathrm{ECC}=0$ ). The proportion differences for the prevalence of the first dental visit by each of the three categories were described.

\section{Ethical considerations}

The research protocol of this study was approved by the Human Research Ethics Committee of the School of Dentistry of the Federal University of Pelotas, Pelotas, Rio Grande do Sul, Brazil (protocol 164/2010), and all mothers have signed an informed consent form to participate in the study.

\section{Results}

The present study sample included 437 mother - child pairs. The refusals comprised $12 \%$ of all mothers who were asked to participate. A total of 93.4\% of children had not visited the dentist. From 29 children that had been to the dentist, $23(79.3 \%)$ went before one year of age, thus only $5.3 \%$ of the total sample has followed the first dental visit recommendation. Table 1 shows the frequency distributions for the socioeconomic and demographic characteristics among children who had not visited the dentist.

Table 1 - Distribution of the characteristics of participants in the study and the use of dental services by children, Pelotas, Brazil, 2011 ( $n=437)$

\begin{tabular}{|c|c|c|c|}
\hline \multirow{2}{*}{ Variables } & \multirow{2}{*}{ Total n (\%) } & \multicolumn{2}{|c|}{ Has never been to the dentist } \\
\hline & & & $p$-value \\
\hline Total & $437(100)$ & $408(93.4)$ & \\
\hline Sex & & & 0.615 \\
\hline Boys & $200(45.9)$ & $188(94,0)$ & \\
\hline Girls & $236(54.1)$ & $219(92.8)$ & \\
\hline Family Income (tertiles) & & & $0.023 *$ \\
\hline 3o Tertile $(2.5-22$ BMW)§ & 140 (32.9) & $124(88,6)$ & \\
\hline $2^{\circ}$ Tertile $(1.4-2.4$ BMW $) \S$ & $142(33.4)$ & $135(95.1)$ & \\
\hline $1^{\circ}$ Tertile $(0-1.3 \mathrm{BMW}) \S$ & $143(33.6)$ & $138(96.5)$ & \\
\hline Maternal level of education & & & 0.004 \\
\hline$\leq 8$ years & $186(42.6)$ & $178(95.7)$ & \\
\hline 9-11 years & $197(45.2)$ & $185(93.9)$ & \\
\hline$\geq 12$ years & $53(12.16)$ & $44(83.0)$ & \\
\hline Number of children & & & $0.068^{*}$ \\
\hline 1 & $228(52.1)$ & $208(91.2)$ & \\
\hline 2 & $136(31.1)$ & $128(94.1)$ & \\
\hline$\geq 3$ & $73(16.7)$ & $72(98.6)$ & \\
\hline Maternal use of dental services & & & $0.002^{*}$ \\
\hline Never goes to the dentist & $51(11.9)$ & $51(100.0)$ & \\
\hline In the presence of pain or a problem & $181(42.1)$ & $174(96.13)$ & \\
\hline Sometimes/Regularly & $198(46.40)$ & $178(89.9)$ & \\
\hline Early childhood caries (ECC $=$ dmfs + white spot lesion) & & & $0.588^{*}$ \\
\hline $\mathrm{ECC}=0$ & $368(84.4)$ & $342(92.9)$ & \\
\hline $\mathrm{ECC}=1$ & $23(5.3)$ & $22(95.6)$ & \\
\hline $\mathrm{ECC} \geq 2$ & $45(10.3)$ & $44(97.8)$ & \\
\hline
\end{tabular}

${ }^{*}$ Fisher's exact test.

Source: authors. 
Figure 1 shows the potential inequalities in prevalence distribution of the first dental visit by the variables investigated (family income, maternal level of education, ECC, number of children, and maternal use of dental services). High disparities in the prevalence proportions of the first dental visit are present in preschool children whose mothers had lower levels of education, families with low socioeconomic status, and mothers who reported not using dental services $(\mathrm{P}<0.05)$. The highest inequality is seen for maternal level of education, whereas mothers in the best category present a superior condition to the others, considering it is the longest line between the categories. There is no statistical association between children's dental visit, dental caries, and number of children $(\mathrm{P}>0.05)$.

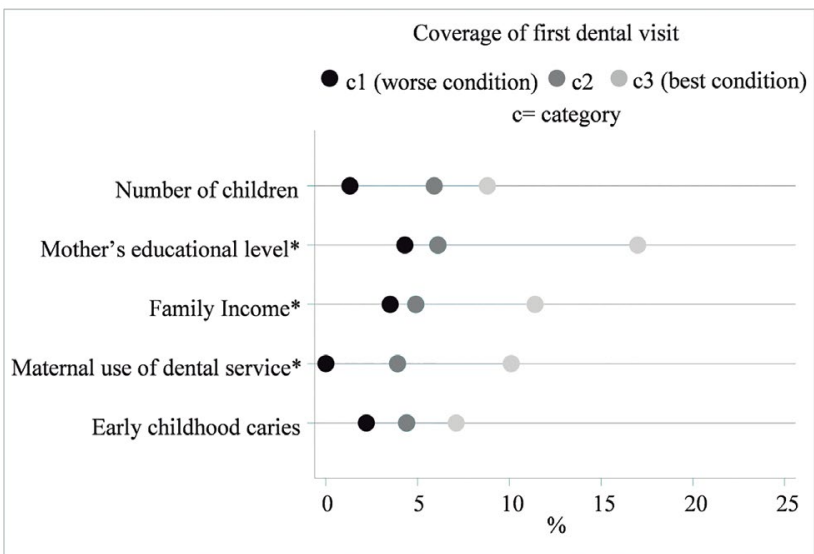

Figure 1 - Equiplot graphic of prevalence rate of the first dental visit and associated characteristics by preschoolers in a city of southern Brazil. The horizontal lines connected the worse condition (black circle) and best condition (light gray circle). The longer the line between the three groups, the higher the absolute inequality.

* Variables with statistically significant association.

Source: authors.

\section{Discussion}

In our study, most mothers had never sought a dentist for their children during their first year of life. This result was consistent with Brazilian studies performed in the same state $\mathrm{e}^{5,8}$ and with studies from other developing countries where a small percentage of children under one year old had already visited a dental office ${ }^{4,7}$.

The American Dental Association has shown an increase in the prevalence of the use of dental service ${ }^{16}$ and this has been one of the indicators to assess the quality of oral health care and to instruct oral health policies. Although the Brazilian oral health policy aims to increase and qualify the access to dental care, the use of these services by preschool children is still lower than among other age groups.

Fernandes and Peres ${ }^{17}$ observed that the numbers of professionals registered in the Brazilian public health system increased along with the coverage of dental appointments for children. Thus, the low prevalence of early use of dental services by children may be related to the failure of public policies in ensuring the availability and accessibility of dental care providers for young children ${ }^{5}$. In addition, there are aspects related to dental professionals who refuse or do not feel comfortable providing care to child patients. Moreover, most pediatricians and general dentists fail to advise patients to seek the dentist by one year of age.

Overall, the use of dental services is influenced by contextual and individual factors, health system characteristics, oral health self-perception, and experience with the use of oral health care ${ }^{7,8,18}$. Among young children that had not experienced any type of dental services, mothers are primarily responsible for taking their children to the dentist. Thereby, mothers who did not obtain dental services for themselves were less likely to take their children to a dentist ${ }^{10}$. Additionally, it has been shown that mothers who had a regular dental appointment for themselves would usually take their children to a dentist more regularly ${ }^{19}$. Parents who had preventive dental visits were also more likely to take their children for early dental visits ${ }^{10}$. In line with these findings, this study identified an association between maternal and child use of dental services. Mothers who had never been to the dentist or do it to solve a problem were less likely to have children that had already visited the dentist.

Evidence have indicated that children who had their first preventive dental visit at an early age were more likely to have subsequent preventive visits and less likely to have subsequent restorative or emergency visits, reducing dental-related health care costs in the future ${ }^{2}$. However, most of the times, taking children for the first visit to the dentist may be motivated after the discovery of any visible dental problem or the child's pain complaint. The literature reported that $25.7 \%$ of the children visit a dentist for the first time due to emergencies caused by discomfort or pain ${ }^{20}$. The most common emergency in pediatric dentistry is dental caries and dental trauma ${ }^{20,21}$. However, in this study, ECC did not play a significant role in the use of dental services. The prevalence of dental caries in this sample was low as most dental caries lesions at this age (18 months or less) are in the initial stages and in most cases do not cause pain and are not perceived by parents, which may explain this result.

Regarding socioeconomic conditions, the results corroborate those of other studies, reinforcing socioeconomic inequalities in the use of dental services also among young children ${ }^{3,4,9}$. Our findings indicated that familiar income and maternal level of education were associated with children that had never visited the dentist. Regarding family income, the dental visits of children of low, medium, and high-income families were compared, and there is a greater disparity between high and medium-income families than between medium and low-income 
families, as shown in the equity figure analysis. Frequent barriers for low-income families to access dental services include financial cost, access to transportation, absence of school policies, and a belief that oral health may not be important to the overall well-being ${ }^{22}$. Unlike our findings, Slayton et al. ${ }^{7}$ showed that children at both ends of the income spectrum were more likely to have had a dental visit prior to age three than those with medium income. According to the authors, families of medium income are not qualified to receive federal aid, while families below the poverty line are more likely to participate in health prevention programs that are included in federal aid.

Another inequality identified in the use of dental services by children was the maternal level of education. In the present study, the higher the maternal level of education, the higher the possibility of a child to have an early dental visit. This result corroborates others studies in the literatu$\mathrm{re}^{7,8,10}$. Low maternal level of education may be associated with low economic status, but it has also been shown that it may be associated with a range of non-economic conditions such as the knowledge on health-related characteristics, which could improve the adoption of healthy habits and access to information concerning essential care for the maintenance of children's oral health ${ }^{23}$.

Although there was no a statistically significant difference, our findings also show that mothers with three children or more are less likely to take them to a dental visit. There are inferences about the effect of number of children on dental caries and subjective oral health ${ }^{24}$, but studies investigating the relationship between children's use of dental services and number of children are scarce. A study among schoolchildren found a relationship between number of children and use of dental services ${ }^{25}$. A possible explanation for this association is that a larger family implies that mothers may pay inappropriate attention and provide less care to their children ${ }^{12}$.

One of the strengths of this study is that mothers were asked about their children's dental visit at a young age, which decreased the memory bias. However, the response bias should not be discarded, considering the findings are based on self-reports. Other limitations of this study include the cross-sectional design, which does not allow a direct cause and effect relationship; also, these findings may not be generalized to the broader community, as this study was not representative of the entire population because the sample was restricted to the urban area of the city. Longitudinal studies are required to draw causal inferences and to assess whether the same findings occur in other countries and regions with different socioeconomic conditions, cultural aspects, or different access to dental services.

The Public Health System in Brazil aims at universal and equal access to actions and health care for the entire population, including oral health. However, these findings potentially suggest a higher inequality in the use of dental services by young children from this system ${ }^{3}$. The right to health care in Brazil has not yet been achieved.

\section{Conclusions}

This study showed that most children aged 1218 months had never been to the dentist. There is a socioeconomic disparity in the use of dental services by young children. Public policies on early dental visits that ensure dental cate availability and accessibility could be encouraged, especially for poor families, less educated mothers, and for mothers who do not make a regular use of dental services.

\section{Acknowledgments}

The authors would like to thank the CNPq (National Council for Scientific and Technological Development; protocol \#306896/2011) for their scholarships and the office of the Municipal Secretary of Health of Pelotas, Rio Grande do Sul, Brazil for their assistance.

\section{Resumo}

Objetivos: avaliar o uso do serviço odontológico em uma cidade do sul do Brasil por crianças de 12 a 18 meses de idade; verificar a relação entre variáveis socioeconômicas, demográficas, uso de serviço odontológico materno e presença de cárie dentária nas crianças; e descrever a cobertura do uso do serviço odontológico por variáveis de disparidade. Sujeitos e método: este estudo transversal foi realizado no Dia Nacional de Vacinação Infantil em doze centros de saúde pública em Pelotas, Rio Grande do Sul, Brasil. Os dados sobre status demográfico e socioeconômico (sexo da criança, número de filhos, renda familiar e educação materna), padrão de uso de serviço odontológico materno e primeira consulta odontológica infantil foram coletados por meio de uma entrevista semiestruturada com as mães. Foi realizado exame clínico para avaliação de cárie dentária nas crianças. O teste Qui-Quadrado e o teste exato de Fisher foram realizados para analisar as associações, e um gráfico equiplot investigou disparidades na cobertura da primeira visita odontológica de pré-escolares. Resultados: a maioria das crianças nunca foi ao dentista (93,4\%). A análise bivariada mostrou que as crianças que nunca foram ao dentista eram de famílias com menor renda, cujas mães tinham níveis baixos de escolaridade e não usavam o serviço de atendimento odontológico. Conclusão: a maioria das crianças de 12 a 18 meses nunca foi ao dentista. Há uma disparidade socioeconômica no uso de serviços odontológicos por crianças pré-escolares.

Palavras-chave: Criança. Cuidados dentários. Odontologia preventiva. Pré-escola. 


\section{References}

1. American Academy of Pediatric Dentistry. Policy on early childhood caries (ecc): Classifications, consequences, and preventive strategies. Pediatr Dent 2008; 30:40-3.

2. Savage MF, Lee JY, Kotch JB, Vann WF, Jr. Early preventive dental visits: Effects on subsequent utilization and costs. Pediatrics 2004; 114:e418-23.

3. Barros AJDB, Bertoldi AD. Desigualdades na utilização e no acesso a serviços odontológicos: Uma avaliação em nível nacional. Ciência \& Saúde Coletiva 2002; 7:709-17.

4. Darmawikarta D, Chen Y, Carsley S, Birken CS, Parkin PC, Schroth RJ, et al. Factors associated with dental services utilization in early childhood. Pediatrics 2014; 133:1594-600.

5. Kramer PF, Ardenghi TM, Ferreira S, Fischer L de A, Cardoso L, Feldens CA. Use of dental services by preschool children in canela, Rio Grande do Sul state, Brazil. Cad Saude Publica 2008; 24:150-6.

6. Pinheiro RST, Torres TZG. Access to oral health services between Brazilian States. Ciência \& Saúde Coletiva 2006; 11:999-1010.

7. Slayton RL, Warren JJ, Levy SM, Kanellis MJ, Islam M. Frequency of reported dental visits and professional fluoride applications in a cohort of children followed from birth to age 3 years. Pediatr Dent 2002; 24:64-8.

8. Ardenghi TM, Vargas-Ferreira F, Piovesan C, Mendes FM. Age of first dental visit and predictors for oral healthcare utilisation in preschool children. Oral Health Prev Dent 2012; 10:17-27.

9. Tapias-Ledesma MA, Jimenez R, Carrasco Garrido P, Gil de Miguel A. Influence of sociodemographic variables on dental service utilization and oral health among the children included in the year 2001 spanish national health survey. J Public Health Dent 2005; 65:215-20.

10. Camargo MB, Barros AJ, Frazao P, Matijasevich A, Santos IS, Peres MA, et al. Predictors of dental visits for routine check-ups and for the resolution of problems among preschool children. Rev Saude Publica 2012; 46:87-97.

11. Pucca GA Jr., Costa JF, Chagas L de D, Sivestre RM. Oral health policies in Brazil. Braz Oral Res 2009; 23(Suppl 1):9-16.

12. Azevedo MS, Romano AR, Dos Santos Ida S, Cenci MS. Knowledge and beliefs concerning early childhood caries from mothers of children ages zero to 12 months. Pediatr Dent 2014; 36:95-9.

13. World Health Organization. Oral health surveys: Basic methods. 3. ed. Geneva: WHO; 1997.

14. Mohebbi SZ, Virtanen JI, Vahid-Golpayegani M, Vehkalahti MM. A cluster randomised trial of effectiveness of educational intervention in primary health care on early childhood caries. Caries Res 2009; 43:110-8.

15. Nyvad B, Machiulskiene V, Baelum V. Reliability of a new caries diagnostic system differentiating between active and inactive caries lesions. Caries Res 1999; 33:252-60.

16. Nasseh K, Vujicic M. Dental services utilization rate continues to increase among children, holds steady among working-age adults and the elderly. Health Policy Institute Research Brief. American Dental Association 2015: 2001-10.

17. Fernandes LS, Peres MA. Association between primary dental services and municipal socioeconomic indicators. Rev Saude Publica 2005; 39:930-6.

18. Baldani MH, Antunes JL. Inequalities in access and utilization of dental services: A cross-sectional study in an area covered by the family health strategy. Cad Saude Publica 2011; 27(Suppl 2):272-83.
19. Goettems ML, Ardenghi TM, Demarco FF, Romano AR, Torriani DD. Children's use of dental services: Influence of maternal dental anxiety, attendance pattern, and perception of children's quality of life. Community Dent Oral Epidemiol 2012; 40:451-8

20. Agostini FG, Flaitz CM, Hicks MJ. Dental emergencies in a university-based pediatric dentistry postgraduate outpatient clinic: a retrospective study. ASDC J Dent Child 2001; 68:316-21, 00-1.

21. Sakai VT, Magalhaes AC, Pessan JP, Silva SM, Machado MA. Urgency treatment profile of 0 to 15 year-old children assisted at urgency dental service from Bauru Dental School, University of Sao Paulo. J Appl Oral Sci 2005; 13:340-4.

22. Kelly SE, Binkley CJ, Neace WP, Gale BS. Barriers to care-seeking for children's oral health among low-income caregivers. Am J Public Health 2005; 95:1345-51.

23. Traebert J, Guimaraes L do A, Durante EZ, Serratine AC. Low maternal schooling and severity of dental caries in brazilian preschool children. Oral Health Prev Dent 2009; 7:39-45.

24. Isong IA, Zuckerman KE, Rao SR, Kuhlthau KA, Winickoff JP, Perrin JM. Association between parents' and children's use of oral health services. Pediatrics 2010; 125:502-8.

25. Onyejaka NK, Folayan MO, Folaranmi N. Barriers and facilitators of dental service utilization by children aged 8 to 11 years in enugu state, nigeria. BMC Health Serv Res 2016; $16: 93$

\section{Corresponding author:}

Marina Sousa Azevedo

Faculdade de Odontologia, Universidade Federal de

Pelotas

Rua Gonçalves Chaves, n. 457, 5ㅇaㅁ

96015-560, Pelotas, Rio Grande do Sul, Brasi

Telefones: +55(53) 32226690 - ramal 135

Fax: +55(53) 32226690

E-mail: marinasazevedo@hotmail.com

Recebido: 17/01/18. Aceito: 26/03/18. 